\title{
The Role of Safety-specific Transformational Leadership in Reducing Near Miss Incidents, Using Safety Climate as a Mediator
}

\section{Ahmad Shahrul Nizam Isha', Muhammad Zeeshan Mirza², Sundas Azeem ${ }^{3}$ and Muhammad Zahid $^{4}$}

\author{
${ }^{1}$ Universiti Teknologi PETRONAS, Malaysia. \\ ${ }^{2}$ Universiti Teknologi PETRONAS, Malaysia. \\ ${ }^{3}$ Shaheed Zulfikar Ali Bhutto Institute of Science and Technology, Pakistan. \\ ${ }^{4}$ City University of Science and Information Technology, Pakistan.
}

\begin{abstract}
Despite the fact that near miss incident plays an important role in the evaluation and improvement of workplace safety, there is limited work on identifying the reasons and providing solutions to curtail near miss incidents at workplace. The current study looks to fill this void by proposing safety-specific leadership approach to combat near miss incidents. Furthermore, the study also discussed that the mechanism through which safety-leadership impact near misses is not direct rather it is achieved by strengthening follower's safety climate perceptions. The practical contributions of the proposed research agenda are also discussed.

Keywords: Safety-specific transformational leadership; Safety climate; Near misses; Malaysia
\end{abstract}

\section{Introduction}

Near misses are considered to be those incidents which have the potential to damage workers or property but does not result in any injury or loss (Gnoni, Andriulo, Maggio, \& Nardone, 2013). They are far less noticeable than accidents/injuries and mostly organizations do not keep a record of them or sometimes difficult to keep track of them. Near misses are defined as "having little if any immediate impact on individuals, processes, or the (Phimister, Oktem, Kleindorfer, \& Kunreuther, 2003 , p. 445). Though near misses does not have a great impact in terms of injury or property loss but they give an overview about the overall safety situation of an organization (Phimister et al., 2003).

But it is difficult to identify near miss incidents at workplace (Reason, 1997). The key factors which prevents them from being reported are: (a) organizational attitude of blaming staff for lack of safety (b) management not paying attention (c) considered them as part of the job (c) wastage of time and resources (Van Der Schaaf \& Kanse, 2004). Thus making it very difficult to collect data on near misses from organizational sources. Due to these issues' studies have employed self-reported measures for near misses (e.g. Clarke, 2006a; Siu et al., 2004) because workers are the most reliable source to recall and remember the near miss events happened to them in the past. The fact that few studies have looked to address the issue of severity related to near misses (Raviv, Fishbain, \& Shapira, 2017) it is imperative to find how leadership can play a role in controlling the near misses at workplace.

In a detailed meta-analysis, Nahrgang et al., (2011) reported that in workplace domain leadership was found to have a reasonable negative association with near misses. However, they also stated that near misses have generally been overlooked as an important safety outcome in the safety literature. The few studies which have tested this relationship has focused on the general leadership, which might not prioritize safety all the time (Mullen \& Kelloway, 2009). Since, near miss incidents at workplace usually happen because of complications in job design, extra effort or load, non-compliance to safety rules and lack of safety guidance (Nahrgang et al., 2011). The role of leader becomes very important, because they are role models (Bass, 1985), and decide about organizational "norms and values" (Bass and Avolio, 1993). When leadership regularly convey through their repeated actions that safety is not to be compromised their followers becomes more 
educated, involved and safety vigilant (Zohar \& Tenne-Gazit, 2008), which reduces the chances safety errors at workplace (Grote, 2012).

The literature recognizes followers of safety-specific transformational leadership to be better safety equipped and have more safety awareness than general leadership (Mullen \& Kelloway, 2009). Given the fact that near misses not necessarily happen because of unsafe condition or acts (Raviv, Shapira, \& Fishbain, 2015) which makes them difficult to affectively managed through any policy. Even if there is a policy or practice, leaders play the most important role in the success of organizational policies and practices (Yukl, 2006) and thus can better educate them how to avoid near miss events.

As most part of human learning is based on one's interactions and environment (Bandura, 1971) therefore leaders can make sure they constantly educate their followers about the importance of safety. Safety-specific transformational leaders will not consider near misses as routine and will try that they do not happen again. Because their focus is on overall safety unlike general leadership which might not consider safety to be that much important in comparison to competing demands like production, profit etc. (Mullen \& Kelloway, 2009).

Hence, the objectives of this paper are manifold: first, given the theoretical description of safety-specific transformational leaders and their uncompromising focus on safety (Barling et al., 2002) they will be in better position to manage the near misses' incidents at workplace. Second, the safety literature has repeatedly reported that the relationship between safety-specific transformational leadership and safety outcomes is not direct rather mediated by safety climate (Clarke, 2013; Clarke \& Ward, 2006; Kelloway, Mullen, \& Francis, 2006; Zohar \& Tenne-Gazit, 2008; Zohar \& Luria, 2004). Based on the empirical evidence we also propose safety climate as a mediator between these relationships by using rational of social learning theory (Bandura, 1971). Lastly, the severe situation regarding accident and injuries in oil and gas industry of Malaysia (Social Security Organization Report, 2016). There is need to have increased focused on the situation of near misses, because they indicate the possibility of future accident and injuries at workplace and thus can prevent them by curtailing near miss incidents.

\section{Research Methodology}

This research is a library research. Its sources are from books, journals and websites in the internet.

\section{Result and Discussion}

Safety-specific transformational leadership and safety climate. The safety literature has repeatedly investigated the paths through which leadership positively affects occupational safety and repeatedly found out that leaders influence workers safety by creating positive safety climate perceptions (Clarke and Ward, 2006; O'Dea and Flin, 2001; Zohar, 2002, 2010). The importance of safety climate perceptions is due to the fact that it conveys to the workers priority given to occupational safety, in comparison to other organization priorities like cost, profit etc. (Zohar \& Tenne-Gazit, 2008).

To create these positive perceptions about safety climate leadership plays the most important role, because of the direct and indirect interaction they have with their followers (Yukl, 2012). Through these interactions they impart their followers about how much importance is given to organizational safety. The literature also confirms that its leaders who create perceptions about organizational values or priorities (Eisenberger, Stinglhamber, Vandenberghe, Sucharski, \& Rhoades, 2002). In this case the safety-specific transformational leaders through their constant focus and communication on safety will shape followers' perceptions of safety climate.

The safety literature also affirms this statement as number of studies have reported favorable effect of safety-specific transformational leadership on safety climate. Barling et al. (2002) seminal study in which they devised the concept of safety-specific transformational leadership reported a strong positive relationship between safety-specific transformational leadership and safety climate. After 
that a number of other studies have also reported strong association between these two constructs (Adjekum, 2017; Hoffmeister et al., 2014; Kelloway et al., 2006; Smith et al., 2016; Starren, 2016; Zacharatos et al., 2005). This empirical proof further signifies the important role safety-specific transformational leadership plays in articulating followers' positive perceptions about safety climate.

Furthermore based on the concept of social learning theory (Bandura, 1971) when safety-specific leaders through verbal communication and their actions demonstrate that safety is an imperative and integral part of their leadership develops an environment in which everyone believes that safety is the first priority and as discussed earlier that followers safety climate perceptions are based on some visible actions which shapes their opinion. Therefore, there is no better way then shaping the safety climate perceptions through the constant communication, motivation and actions of safety-specific transformational leader.

Preposition 1: Safety-specific transformational leadership will be positively associated with safety climate.

Safety climate and near misses. Among the safety outcomes, near misses are the most difficult one's to define and categorized (Reason, 1997). The difficulty in identifying near misses is that, their consequences are not severe, so workers do not report them to their organization (Tucker, Diekrager, Turner, \& Kelloway, 2014). Since near misses are events which could have resulted in an accident or injury but did not, therefore considered less important by workers. Although near misses might not result in property or personal damage, but they are an integral part of occupational safety (Phimister et al., 2003) cause near miss events are those which in future can result in an accident or injury.

However the studies testing the relationship between safety climate and near misses are scarce. Even overall in the safety literature the studies on near misses are far and few between, and we hardly see near misses making an appearance in some of the current reviews on occupational safety (e.g. Clarke, 2013; Pilbeam et al., 2016). Even though the safety research recommend that near misses must be studied to have an overall view of safety situation in the organization (Phimister et al., 2003).

In one of the early studies, Barling et al. (2002) found a significant negative relationship between safety climate and near misses. Subsequently, Mearns, Whitaker, and Flin (2003) also reported similar findings, and these results were further verified by the study of (Kelloway et al., 2006). Moving forward in a study by (Cavazza \& Serpe, 2009) safety climate was found to significantly decreased the near misses' incidents at workplace. To sum up the empirical work in a comprehensive meta-analysis, Nahrgang et al. (2011) reported a substantial variance (25\% to $49 \%)$ caused by safety climate in near misses.

However, in the most recent review on safety outcomes (Cornelissen, Hoof, \& Jong, 2017) stated that safety climate and near miss's relationship needs more rigorous investigation as the existing literature is very limited and requires further investigation to establish this relationship. Although the limited literature does provide evidence about safety climate and near miss's relationship. As part of the social belief process (Bandura, 1977) when workers consider that safety behaviors are valued and appreciated it instill positive safety climate perceptions and creates an overall environment, where everyone is sensitive about safety and make sure that safety is not compromised for competing demands and will ultimately result in fewer near miss incidents.

Preposition 2: Safety climate will be negatively associated with near misses.

Safety climate as a mediator between safety-specific transformational and near misses. As compared to occupational accidents and injuries, gathering data on near misses is far more difficult and complex (Yang, Ahn, Vuran, \& Aria, 2015) although assessing near misses' situation can be equally or more important than accidents or injuries. Near miss incidents provide insight into the causes of accidents or injuries and help in evading future safety mishaps (Cambraia, Saurin, \& Formoso, 2010). In various industries information on near misses is used to correct flaws in the 
system to prevent future accident and injuries (Wright \& Van Der Schaaf, 2004). Thus it is imperative to evaluate near miss incidents, as the overall situation of workplace safety cannot be explained without assessing them (Yang et al., 2015).

The empirical work using safety climate as a mediator between safety-specific transformational leadership and near misses is limited. One of the earliest studies reported the mediating role of safety climate (Barling et al., 2002). However, their operationalization of near misses was only specific to the restaurant industry and was termed as 'safety related events' owing to the nature of near miss incidents in that specific setting. Replicating the work of, Barling, Kelloway et al. (2006) also used the 'safety related events' terminology. Both studies reported that safety climate mediates the relationship between safety-specific transformational leadership and near misses. However, owing to industry specific operationalization of near misses, these results can only be taken as an indication that safety-specific transformational leadership will have a beneficial effect on near misses via safety climate.

Near misses mostly happen due to safety negligence of workers or unsafe working conditions (Gnoni et al., 2013). As leaders act as role models (Bass, 1985), and "cultural norm arises and change because of what leader focus their attention on" (Bass \& Avolio, 1993, p. 113), leadership assumes a central role in improving the near misses' situation. Their emphasis on safety enables followers to be extra vigilant and not to take safety lightly. Since the social learning process (Bandura, 1971) also explains that employee's actions are based on how rewarding environment is regarding those actions. Hence, when compliance to safety norms and procedures are emphasized and rewarded from the leaders it will instill positive perceptions about safety climate which will ultimately result in lesser number of near miss incidents.

Preposition 3: Safety climate mediates the relationship between safety-specific transformational leadership and near misses.

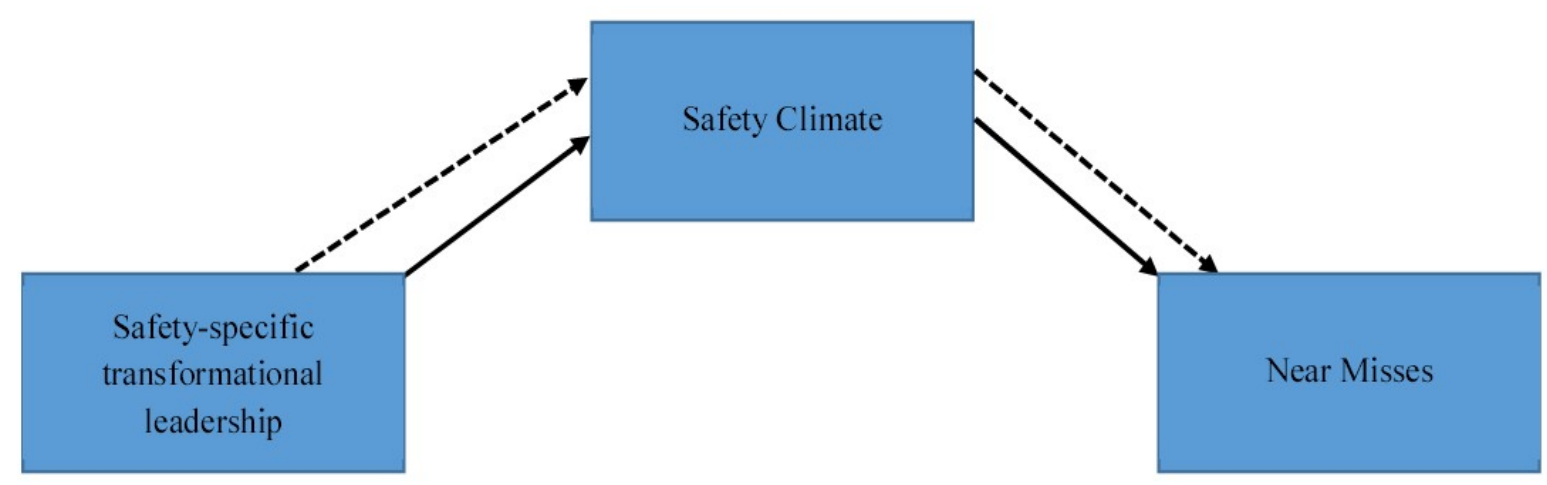

Figure 1: The proposed framework of the study

\section{Conclusion}

The frequency of near miss incidents shows organizational seriousness about workplace safety (Phimister et al., 2003). If the frequency is higher it highlights that these incidents are not taken seriously thus showing an intended negligence towards safety lapses which can cause serious accidents and injuries in the future (Yang et al., 2015). As the near miss incidents given an opportunity to the organization to plug the gaps, improve working condition, and put more emphasis on safety so that their workers are clear that safety is not to be compromised at any cost.

However, few studies have looked to address the issue of near misses (Raviv et al., 2017), and current study looks to fill this gap by proposing a leadership-based approach to curtail near misses at workplace. The safety-specific leadership has an unbending attitude towards workplace safety (Mullen \& Kelloway, 2009) which makes it most relevant to combat these incidents at workplace. When safety-leaders regularly communicate and convey the importance of safety to their followers, it strengthens belief that safety is not to be compromised for any competing demands (safety 
climate), and strong safety climate perceptions will decrease near miss incidents at workplace.

The study will make important practical contribution to resolve the issue of workplace safety in oil and gas industry of Malaysia. The high number of accidents and injuries in the industry, shows negligence towards tackling the issue of near miss incidents. However, identifying and tackling near miss incidents is a complicated issue for the organizations. Thus, this study provides a safety-leadership approach for the Malaysian oil and gas industry to combat near miss incidents. The safety literature clearly confirms that adopting safety leadership is both manageable and cost effective for organizations. Therefore, moving forward by adopting safety-specific transformational leadership, oil and gas industry of Malaysia can not only reduce near miss incidents but allow them to plug the safety-lapse and improve working condition, can avoid the possibility of future accidents and injuries.

\section{References}

Adjekum, D. K. (2017). An Evaluation of the Relationships between Collegiate Aviation Safety Management System Initiative, Self-Efficacy, Transformational Safety Leadership and Safety Behavior mediated by Safety Motivation. International Journal of Aviation, Aeronautics, and Aerospace, 4(2).

Bandura, A. (1971). Social Learning Theory. Social Learning Theory. Englewood Cliffs. https://doi.org/10.1111/j.1460-2466.1978.tb01621.x

Bandura, A. (1977). Self-efficacy: Toward a Unifying Theory of Behavioral Change. Psychological Review, 84(2), 191215.

Barling, J., Loughlin, C., \& Kelloway, E. K. (2002). Development and test of a model linking safety-specific transformational leadership and occupational safety. Journal of Applied Psychology, 87(3), 488 496. https://doi.org/10.1037//0021-9010.87.3.488

Bass, B. (1985). Leadership and performance beyond expectations. New York: Free Press.

Bass, B., \& Avolio, B. (1993). Transformational Leadership and Organizational Culture. Public Administration Quarterly, 17(1), 112121.

Cambraia, B., Saurin, A., \& Formoso, T. (2010). Identification, analysis and dissemination of information on near misses: A case study in the construction industry. Safety Science, 48(1), 91 99. https://doi.org/10.1016/j.ssci.2009.06.006

Cavazza, N., \& Serpe, A. (2009). Effects of safety climate on safety norm violations: exploring the mediating role of attitudinal ambivalence toward personal protective equipment. Journal of Safety Research, 40(4), 277 283. https://doi.org/10.1016/j.jsr.2009.06.002

Clarke, S. (2006). Safety climate in an automobile manufacturing plant. Personnel Review, 35(4), 413 430. https://doi.org/10.1108/00483480610670580

Clarke, S. (2013). Safety leadership: A meta-analytic review of transformational and transactional leadership styles as antecedents of safety behaviours. Journal of Occupational and Organizational Psychology, 86(1), 22 49. https://doi.org/10.1111/j.2044-8325.2012.02064.x

Clarke, S., \& Ward, K. (2006). The role of leader influence tactics and safety climate in engaging employees' safety participation. Risk Analysis, 26(5), 11751185.

Cornelissen, P. A., Hoof, J. J. Van, \& Jong, M. D. T. De. (2017). Determinants of safety outcomes and performance: A systematic literature review of research in four high-risk industries. Journal of Safety Research, 62, 127 141. https://doi.org/10.1016/j.jsr.2017.06.009

Eisenberger, R., Stinglhamber, F., Vandenberghe, C., Sucharski, I. L., \& Rhoades, L. (2002). Perceived supervisor support: Contributions to perceived organizational support and employee retention. Journal of Applied Psychology, 87(3), 565573. https://doi.org/10.1037//0021-9010.87.3.565

Gnoni, M. G., Andriulo, S., Maggio, G., and Nardone, P. (2013). "Lean occupational" safety: an application for a Near-miss Management System design. Safety Science, 53, 96104.

Hoffmeister, K., Gibbons, A. M., Johnson, S. K., Cigularov, K. P., Chen, P. Y., \& Rosecrance, J. C. 
(2014). The differential effects of transformational leadership facets on employee safety. Safety Science, 62, 68 78. https://doi.org/10.1016/j.ssci.2013.07.004

Kelloway, K., Mullen, J., \& Francis, L. (2006). Divergent effects of transformational and passive leadership on employee safety. Journal of Occupational Health Psychology, 11(1), 7686. https://doi.org/10.1037/1076-8998.11.1.76

Mearns, K., Whitaker, S. M., \& Flin, R. (2003). Safety climate, safety management practice and safety performance in offshore environments. Safety Science, 41(8), 641680.

Mullen, J., \& Kelloway, E. K. (2009). Safety leadership: A longitudinal study of the effects of transformational leadership on safety outcomes. Journal of Occupational and Organizational Psychology, 82(2), 253 272. https://doi.org/10.1348/096317908X325313

Nahrgang, J. D., Morgeson, F. P., \& Hofmann, D. A. (2011). Safety at work: A meta-analytic investigation of the link between job demands, job resources, burnout, engagement, and safety outcomes. Journal of Applied Psychology, 96(1), 71 94. https://doi.org/10.1037/a0021484

O'Dea, A., and Flin, R. (2001). Site managers and safety leadership in the off-shore oil and gas industry. Safety Science, 37, 3957.

Phimister, J. R., Oktem, U., Kleindorfer, P. R., \& Kunreuther, H. (2003). Near-Miss Incident Management in the Chemical Process Industry. Risk Analysis, 23(3).

Pilbeam, C., Doherty, N., Davidson, R., \& Denyer, D. (2016). Safety leadership practices for organizational safety compliance: Developing a research agenda from a review of the literature. Safety Science, 86, 110 121. https://doi.org/10.1016/j.ssci.2016.02.015

Raviv, G., Fishbain, B., \& Shapira, A. (2017). Analyzing risk factors in crane-related near-miss and accident reports. Safety Science, 91, 192 205. https://doi.org/10.1016/j.ssci.2016.08.022

Raviv, G., Shapira, A., \& Fishbain, B. (2015). Analysing and modeling near misses in crane-work environments. In ARCOM Doctoral Workshop on Health, Safety and Wellbeing, Association of Researchers in Construction Management, Edinburgh, UK (pp. 37 49).

Reason, J. (1997). Managing the Risks of Organizational Accidents. Ashgate, Aldershot, UK.

Siu, O. L., Kong, H., \& Phillips, D. R. (2004). Safety climate and safety performance among construction workers in Hong Kong : The role of psychological strains as mediators, 36, 359 366. https://doi.org/10.1016/S0001-4575(03)00016-2

Smith, T. D., Eldridge, F., \& DeJoy, D. M. (2016). Safety-specific transformational and passive leadership influences on firefighter safety climate perceptions and safety behavior outcomes. Safety Science, 86, 92 97. https://doi.org/10.1016/j.ssci.2016.02.019

Social Security Organization Report. (2016). Retrieved from https://www.perkeso.gov.my/index.php/en/report/annual-report

Starren, M. (2016). Multicultural Working Teams and Safety Awareness: How Effective Leadership can Motivate Safety Behaviour. Psychology, (July), 10151022.

Tucker, S., Diekrager, D., Turner, N., \& Kelloway, E. K. (2014). Work-related injury underreporting among young workers: Prevalence, gender differences, and explanations for underreporting. Journal of Safety Research, 50, $67 \quad 73$. https://doi.org/10.1016/j.jsr.2014.04.001

Van Der Schaaf, T., \& Kanse, L. (2004). Biases in incident reporting databases: an empirical study in the chemical process industry. Safety Science, 42(1), 5767.

Wright, L., \& Van Der Schaaf, T. (2004). Accident versus near miss causation: A critical review of the literature, an empirical test in the UK railway domain, and their implications for other sectors. Journal of Hazardous Materials, $111\left(\begin{array}{lllll}1 & 3\end{array}\right), \quad \begin{array}{ll}105 & 110 .\end{array}$ https://doi.org/10.1016/j.jhazmat.2004.02.049

Yang, K., Ahn, C. R., Vuran, M. C., \& Aria, S. S. (2015). Semi-supervised near-miss fall detection for ironworkers with a wearable inertial measurement unit. Automation in Construction, 68, 194 202. https://doi.org/10.1016/j.autcon.2016.04.007

Yuki, G. (2012). Effective Leadership Behavior: What We Know and What Question need more 
Attention. Academy of Management Perspectives, 26(4), 6685.

Yukl, G. A. (2006). Leadership in organizations (6th ed.). Upper Saddle River, NJ: Prentice Hall.

Zacharatos, A., Barling, J., \& Iverson, R. D. (2005). High-performance work systems and occupational safety. The Journal of Applied Psychology, 90(1), $77 \quad 93$. https://doi.org/10.1037/0021-9010.90.1.77.

Zohar, D. (2002). The Effects of Leadership Dimensions, Safety Climate, and Assigned Priorities on Minor Injuries in Work Groups. Journal of Organizational Behavior, 23(1), 7592. https://doi.org/10.1002/job.

Zohar, D. (2010). Thirty years of safety climate research: Reflections and future directions. Accident Analysis and Prevention, 42(5), 15171522. https://doi.org/10.1016/j.aap.2009.12.019

Zohar, D., \& Luria, G. (2004). Climate as a Social-Cognitive Construction of Supervisory Safety Practices: Scripts as Proxy of Behavior Patterns. Journal of Applied Psychology, 89(2), 322 333. https://doi.org/10.1037/0021-9010.89.2.322

Zohar, D., \& Tenne-Gazit, O. (2008). Transformational leadership and group interaction as climate antecedents: a social network analysis. The Journal of Applied Psychology, 93(4), 744757. https://doi.org/10.1037/0021-9010.93.4.744 